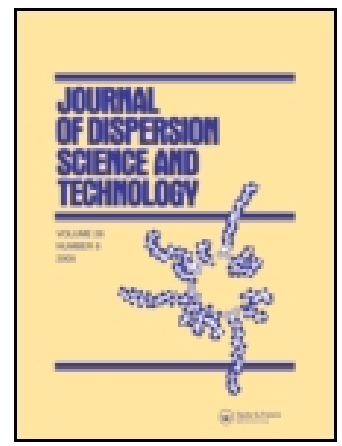

Journal of Dispersion Science and Technology

ISSN: 0193-2691 (Print) 1532-2351 (Online) Journal homepage: http://www.tandfonline.com/loi/ldis20

\title{
Interaction of Sodium Dodecyl Sulfate with Poly(ethyleneimine) in Bulk Solution and at the Air-Solution Interface
}

\section{Aylin Şakar-Deliormanlı}

To cite this article: Aylin Şakar-Deliormanlı (2009) Interaction of Sodium Dodecyl Sulfate with Poly(ethyleneimine) in Bulk Solution and at the Air-Solution Interface, Journal of Dispersion Science and Technology, 31:1, 23-30, DOI: 10.1080/01932690903123692

To link to this article: http://dx.doi.org/10.1080/01932690903123692

曲 Published online: 09 Dec 2009.

Submit your article to this journal $[\pi$

Џll Article views: 46

Q View related articles $\longleftarrow$

Citing articles: 1 View citing articles $\square$ 


\title{
Interaction of Sodium Dodecyl Sulfate with Poly(ethyleneimine) in Bulk Solution and at the Air-Solution Interface
}

\author{
Aylin Şakar-Deliormanlı \\ Izmir Institute of Technology, Chemical Engineering Department, Urla, Izmir, Turkey
}

\begin{abstract}
Interaction of sodium dodecyl sulfate (SDS) with the cationic polyelectrolyte poly(ethyleneimine) (PEI) was investigated in this study. Turbidity measurements were performed in order to analyze the interaction and complex formation in bulk solution as a function of polymer concentration and $\mathrm{pH}$. Surface tension measurements were made to investigate the properties of SDS/PEI/ water mixtures at air/solution interface. Results revealed that SDS/PEI complexes form in solution depending on the surfactant and polymer concentration. A decrease was observed in surface tension values in the presence of SDS/PEI mixtures compared to the values of pure SDS solutions. Both solution and interfacial properties exhibited $\mathrm{pH}$ dependent behavior. A shift was seen in the critical micelle concentration of SDS solutions as a function of PEI concentration and solution pH. Monovalent and divalent salt additions showed some influence on the interfacial properties of SDS solutions in the presence of PEI.
\end{abstract}

Keywords Micelles, poly (ethyleneimine), sodium dodecyl sulfate, surface tension, surfactant/ polyelectrolyte mixtures

\section{INTRODUCTION}

Investigation of the interaction between the surfactants and polymers in aqueous environment is crucial for many applications such as detergents, paints, pharmaceutical, drug delivery, mineral processing, and other chemical industries. ${ }^{[1-3]}$ Therefore, properties of mixtures of surfactants and oppositely charged polymers in aqueous solutions gained much interest in scientific field in recent years and intensive effort has been made to characterize the nature of these interactions. ${ }^{[4-8]}$

In the absence of polymers, surfactant molecules aggregate in aqueous solutions to form micelles at concentrations beyond a critical micelle concentration. ${ }^{[9,10]}$ When water soluble polymers are added to the surfactant solutions, they may modify the free energy contributions during the surfactant micellization. ${ }^{[1]}$ In this situation, single dispersed polymer molecules, intermolecular complexes between the polymer and surfactant, single dispersed surfactant molecules, and polymer free surfactant aggregates may exist in solution. ${ }^{[9,10]}$ Ionic polymers having similar charge with the surfactant molecules show moderate effect however, polymers having an opposite charge may cause more important effects in surfactant solutions. ${ }^{[1,11]}$

Received 5 June 2008; accepted 28 June 2008.

Address correspondence to Aylin Şakar-Deliormanlı, Izmir Institute of Technology, Chemical Engineering Department, Gulbahce Koyu, Urla, 35430 Izmir, Turkey. E-mail: aylindeliormanli @iyte.edu.tr or adeliorm@uiuc.edu
Among the branched polymers, polyethyleneimine (PEI) is of special interest because it is widely used as dispersion stabilizer, flocculation agent, adhesive, and in gene delivery therapy ${ }^{[12,13]}$ Similarly, SDS is an anionic surfactant that is commonly used in mineral processing, flotation, and manufacturing many chemical products. ${ }^{[14-17]}$ The interactions between PEI and SDS have been investigated in the past. ${ }^{[13]}$ Windsor et al. studied the adsorption of SDS in the presence of PEI. ${ }^{[18]}$ More recently, Penfold et al. reported the effect of $\mathrm{pH}$ and polyelectrolyte architecture on the adsorption behavior of SDS/PEI mixtures at the airsolution interface using surface tension and neutron reflectivity. Results of the study revealed that there is strong hydrophobic interaction between the SDS and PEI in addition to the electrostatic interactions. ${ }^{[19]}$

Zakharova et al. studied on the self-organization and catalytic activity of SDS/PEI/water system. They found that hydrophobic interactions contribute substantially to the formation of SDS/PEI complexes. ${ }^{[20]}$ Dedinaite et al. reported the effect of SDS on the properties of adsorbed layers of PEI. According to their study interfacial association between PEI and SDS is different from that observed for other cationic polyelectrolyte-surfactant complexes. ${ }^{[12]}$ The impact of electrolyte on the adsorption of SDS/PEI complexes at air-solution interface has been investigated by Penfold and coworkers. ${ }^{[21]}$ The addition of $\mathrm{NaCl}$ is shown to have a significant effect on the adsorption of these complexes. Similarly, the binding isotherm of SDS on a PEI 
was determined by an equilibrium dialysis method by Meszaros et al. ${ }^{[4]}$ In the study, dynamic light scattering (DLS), electrophoretic mobility, and coagulation kinetics measurements were performed in order to monitor the changes in the charge and the size of SDS/PEI complexes.

Although there is extensive research in literature on the interfacial properties and adsorption behavior of ionic polyelectrolyte and oppositely charged surfactant mixtures more profound understanding in necessary. Especially SDS/PEI/water system should be investigated in detail to explain the mechanisms underlying complex formation and surface properties. In this study solution and surface behavior of aqueous SDS/PEI mixtures has been investigated using surface tension and turbidity measurements. Effect of $\mathrm{pH}$ and addition of electrolyte on the bulk and interfacial properties were studied.

\section{EXPERIMENTAL}

\subsection{Materials}

SDS, $\mathrm{NaOSO}_{3} \mathrm{C}_{12} \mathrm{H}_{25}$ (>98\%; MW: $\left.288,4 \mathrm{~g} / \mathrm{mol}\right)$ was obtained from Aldrich Chemical Company (USA). Cationic polyelectrolyte poly(ethyleneimine) PEI $\left(M_{W} \sim 2000 \mathrm{~g} /\right.$ mol) was supplied (Polysciences, Inc., USA) as a concentrated liquid $(99 \%)$, which was diluted with deionized water to form a concentrated aqueous solution. Figures $1 \mathrm{a}$ and $1 \mathrm{~b}$ show the chemical structure of sodium dodecyl sulfate and poly(ethyleneimine) used in the study. Poly(ethyleneimine) is a highly branched polyamine that contains primary, secondary, and tertiary amine groups in a $\sim 1: 2: 1$ ratio. $^{[18]}$ During the experiments all $\mathrm{pH}$ adjustments were made using certified $1.0 \mathrm{M}$ solutions of $\mathrm{KOH}$ and $\mathrm{HNO}_{3}$ (Fisher Scientific, USA). Stock solutions of 1.0 M Sodium chloride (Fisher Scientific), and $1.0 \mathrm{M}$ Calcium chloride (Fisher Scientific) were prepared with deionized water and these solutions were utilized through the experiments. Nano pure

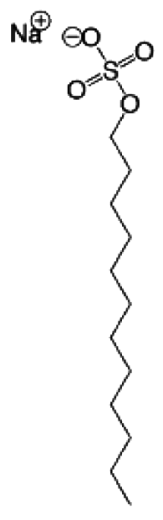

(a)

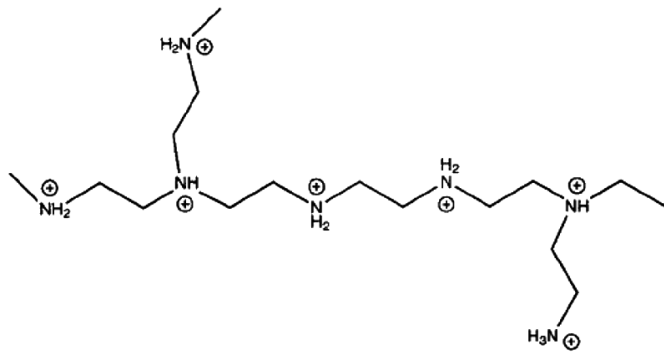

(b)
FIG. 1. Chemical structure of the (a) SDS (from ref. 22), (b) PEI (from ref. 23). water having conductivity of $16.4(\Omega \cdot \mathrm{cm})^{-1}$ was used for all experiments.

\subsection{Method}

\subsubsection{Solution Preparation}

SDS/PEI mixtures were prepared by adding specified amount PEI solution to the SDS solutions in the range of $10^{-7} \mathrm{M}$ to $5 \times 10^{-2} \mathrm{M}$. Final PEI concentration in the surfactant/polymer mixture was between $20 \mathrm{ppm}$ and $2000 \mathrm{ppm}$. Solution mixtures were stirred for 5 minutes using a magnetic stirrer at room temperature then rest for 1 minute prior to the measurements.

\subsubsection{Characterizations}

Interfacial properties of SDS/PEI/water mixtures was investigated using a tensiometer (Kruss-Digital K 10ST, Hamburg, Germany) employing De Nouy ring method. The measurements were performed at $25^{\circ} \mathrm{C}$ and the platinum ring was flamed until it glowed red before each measurement to avoid organic contamination. Repeated measurements were made until equilibrium was reached.

Bulk properties of SDS/PEI aqueous solutions were studied using a turbidimeter (WTW555, Germany). The turbidimeter used in the study measures the light scattered at an angle to the incident light beam and then relate this angle scattered light to the samples turbidity. It measures $90^{\circ}$ scatter and is called nephelometric turbidimeter. Turbidity measured in this way is stated in nephelometric turbidity units (NTU). ${ }^{[2]}$ Measurements were performed using nephelometric ratio method and results were recorded in terms of NTU with \pm 2 of value or \pm 0.01 NTU accuracy.

\section{RESULTS AND DISCUSSION}

\subsection{Bulk Properties of SDS/PEI Solution Mixtures}

The standard method for determining the charge on a polymer as a function of $\mathrm{pH}$ is to titrate the polymer using acid or base, and record the $\mathrm{pH}$. Titration data may be transformed to the Henderson-Hasselbach equation suitable for polyelectrolytes: ${ }^{[25]}$

$$
\log K_{i}=\log K_{i}^{0}+(n-1) \log \left(\frac{1-\alpha}{\alpha}\right)
$$

where $\log K_{i}$ is the effective protonation constant of the polymer, $\log K_{i}^{0}$ is the protonation of the completely unionized polymer, and $\alpha$ is the degree of protonation. $n$ is a parameter that accounts for neighboring group effects in the protonation process.

Potentiometric titrations were performed in order to investigate the fraction of ionized sites in PEI as a function of $\mathrm{pH}$ in a previous study. ${ }^{[26]}$ Accordingly, PEI is fully charged at about $\mathrm{pH} 2$ (see Figure 2) and at $\mathrm{pH} 6$ it 


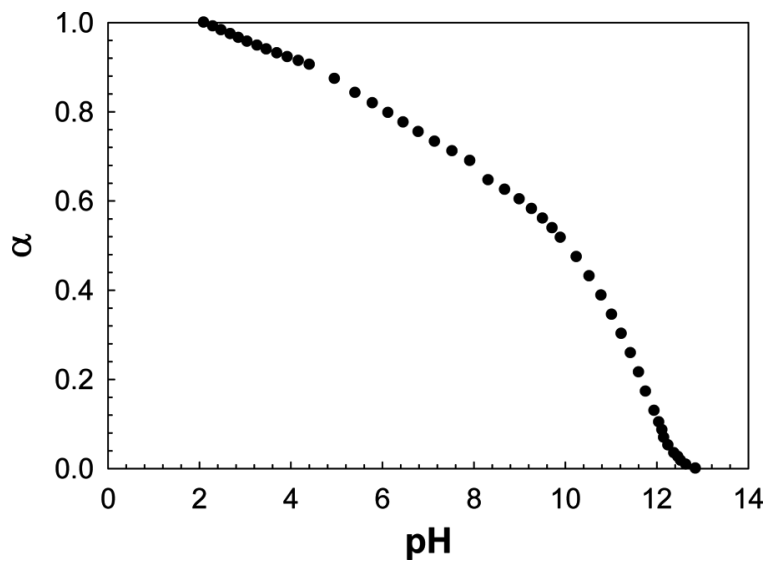

FIG. 2. The ionization degree of PEI solution as a function of $\mathrm{pH}{ }^{[26]}$

is positively charged with approximately $50 \%$ of the amine groups are protonated.

In the study to get an idea on the association between PEI and SDS in bulk solution the turbidity of single surfactant and polyelectrolyte-surfactant mixtures were measured as a function of SDS and PEI concentration. Figure 3 shows the turbidity values of the SDS solutions as a function of surfactant concentration in the absence of PEI. According to the figure starting from the CMC the turbidity of pure SDS solutions rises sharply followed by a decrease at higher surfactant concentrations. Similarly, Bayrak $^{[27]}$ reported that starting at the CMC, the solution's light-scattering ability (turbidity) rises sharply. These facts indicate that above the CMC a substantial portion of the solute ions are aggregated to form units of colloidal size called micelles. Dilution of the solution below the CMC eliminates the micelles, and so micelle formation is reversible. ${ }^{[27]}$ It was interesting to observe that by the addition of

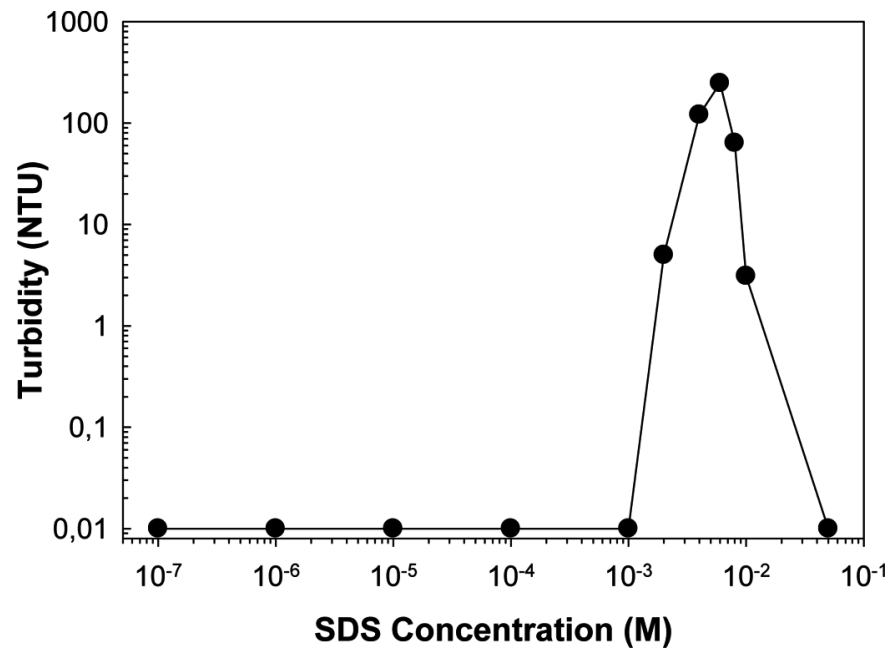

FIG. 3. The turbidity of pure SDS solutions as a function of surfactant concentration.

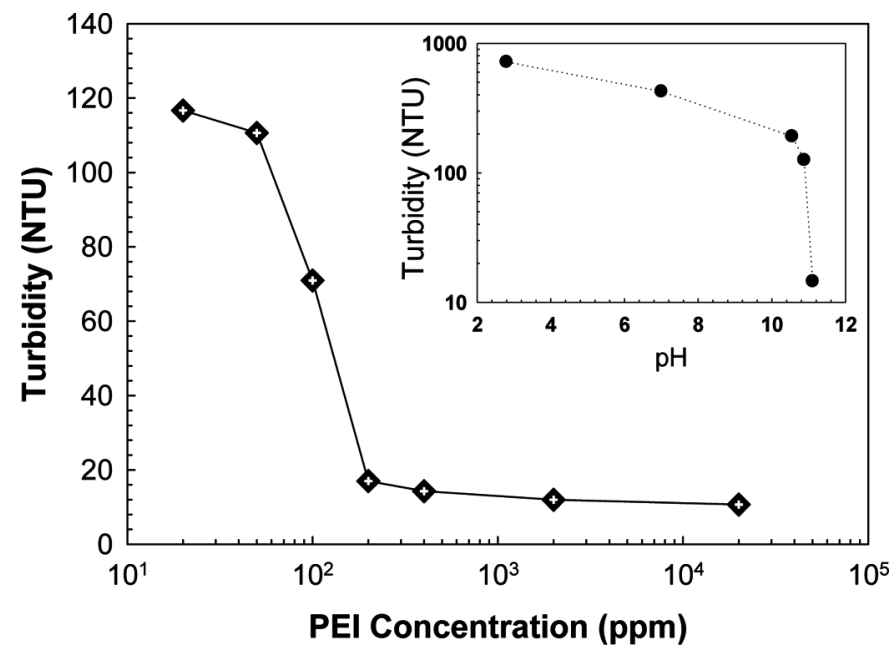

FIG. 4. Effect of PEI concentration on the turbidity of SDS/PEI solution mixtures, SDS at $6 \times 10^{-3} \mathrm{M}$. Insert plot- Effect of $\mathrm{pH}$ on the turbidity of SDS/PEI solution mixture, SDS $6 \times 10^{-3} \mathrm{M}$ and PEI $400 \mathrm{ppm}$.

PEI to the SDS solution having highest turbidity value (at $\left.6 \times 10^{-3} \mathrm{M}\right)$ a gradual decrease started in turbidity values. At very high PEI concentrations the SDS solutions were nearly transparent. However, this was only valid for the SDS solutions in the range of $4 \times 10^{-3} \mathrm{M}$ to $8 \times 10^{-3} \mathrm{M}$ (see Figure 4). The decrease in turbidity values may be attributed to the change in the charge of SDS solutions by the PEI addition. It is known that turbidity measurements in dilute polymer solutions coincides closely with the point of zero mobility. The dispersed aggregates are stable when their net charge is high but they flocculate or sediment when their charge is low. ${ }^{[28]}$

Figure 5 shows the effect of surfactant and polyelectrolyte concentration on the turbidity of SDS/PEI mixtures.

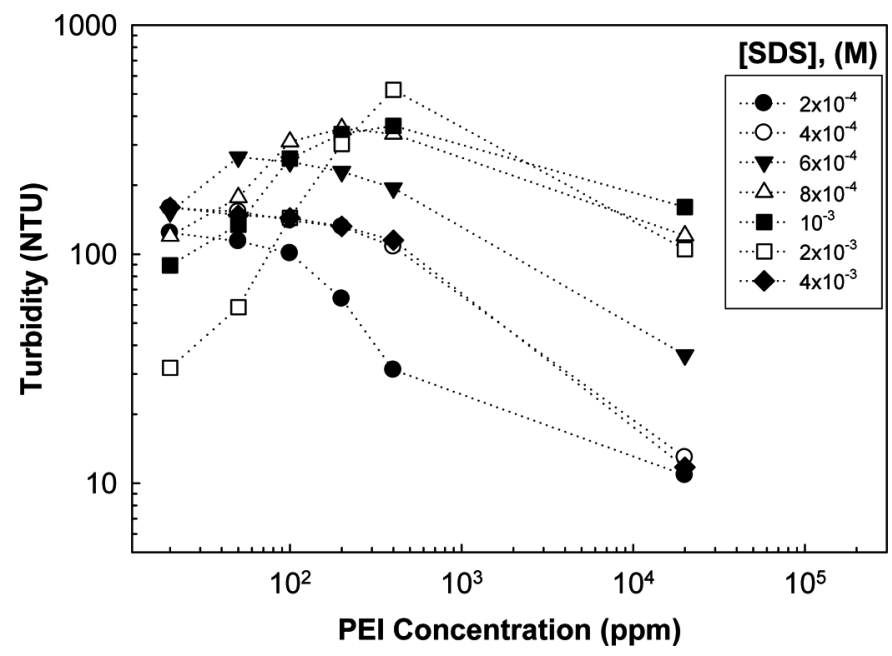

FIG. 5. Turbidity values of SDS/PEI mixtures as a function SDS and PEI concentration. 
The solution becomes turbid in an SDS solution (starting from $2 \times 10^{-4} \mathrm{M}$ SDS concentration) in the presence of PEI. Additionally, precipitates form if the concentration of SDS is higher than a critical concentration. The appearance of precipitation can be explained by charge neutralization. ${ }^{[4]}$ It is also known that when a surfactant is added to a polyelectrolyte solution the surfactant forms aggregates adsorbed to the polymer chains above a critical surfactant concentration. ${ }^{[29]}$ At this critical association concentration combined aggregation of surfactant and polymer molecules form in solution. In the case of long polymers the chains undergo globalization with inclusion of surfactant aggregates. The formation of these complex structures continues up to a saturation concentration. Above this concentration micelles unbound to the polymer formed in solution with the surfactant/polymer complexes. ${ }^{[20]}$

Results of the current work also showed that PEI concentration is greatly influence the precipitate formation because at very high PEI concentrations rod like precipitate formation initiated. Therefore, it is possible to conclude that the system can be described as thermodynamically stable solution of the solvated SDS/PEI complex molecules at low surfactant concentrations. Above a critical surfactant concentration the system becomes unstable colloidal dispersions of collapsed SDS/PEI particles and this results in precipitation. Although it is not shown in Figure 5, at higher surfactant concentrations the surfactant adsorption may takes place onto the PEI surface, and dispersion of SDS/PEI particles may occur due to electrostatic stabilization. ${ }^{[30]}$ Figure 6 shows schematically the possible interaction mechanism between the SDS and PEI in bulk and at the interface at high surfactant concentrations.

The formation of three dimensional structures in aqueous solutions can be attributed to the electrostatic/ hydrophobic interactions or combination of a polymer backbone and electrostatic interactions. ${ }^{[31]}$ Bastardo et al. performed small-angle neutron scattering measurements in solutions containing highly charged PEI at low $\mathrm{pH}$ and low SDS concentrations. Results indicated the presence of disk shape aggregates. The aggregates change to a more complex three-dimensional structure with increasing surfactant concentration. ${ }^{[32]}$ Similarly, in the current study three dimensional structures were observed

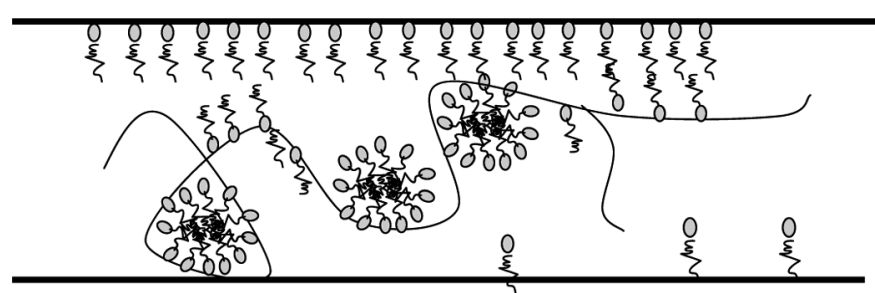

FIG. 6. Schematic representation of the interaction between the PEI and SDS at high surfactant concentration. at a SDS concentration starting from $4 \times 10^{-3} \mathrm{M}$ in the presence of PEI (400 ppm) at $\mathrm{pH} 9$.

The rate of precipitation is also dependent on the method of solution preparation. Mezei et al. ${ }^{[30]}$ investigated the effect of mixing on the complex formation in PEI/SDS system. It was found that at large excess of surfactant colloidal dispersions of PEI/SDS particles forms via extremely rapid mixing of the components. However, applications of less efficient mixing may result in large clusters of the PEI/SDS particles. For aqueous mixture of SDS and cationic polyelectrolyes the state of the system was also found to depend on the order of addition of the components. ${ }^{[4]}$

In the current study effect of different mixing protocols on the complex formation between SDS and PEI was not investigated. However, during solution preparation step specified amount of PEI was added to the SDS solution and efficient mixing was applied for 5 minutes. But it is clear that based on the previous studies the solution preparation method followed in this study may have some influence on the bulk properties and complex formation behavior between SDS and PEI. On the other hand, formation of transparent solution mixtures at large surfactant concentrations and at high $\mathrm{pH}$ values implies that the mixing protocol applied in this study is suitable to prepare SDS/PEI solution mixtures.

\subsubsection{Effect of $\mathrm{pH}$ on the Bulk Properties}

Figure 7 gives the effect of solution $\mathrm{pH}$ on the bulk properties of SDS solutions in the presence of PEI (400 ppm). It is possible to analyze the graph by dividing three regions depending on the complexation behavior. In region A, a gradual increase was observed in turbidity values depending on the SDS concentration at all $\mathrm{pH}$ values. Turbidity was slightly lower at $\mathrm{pH} 10$ (which is

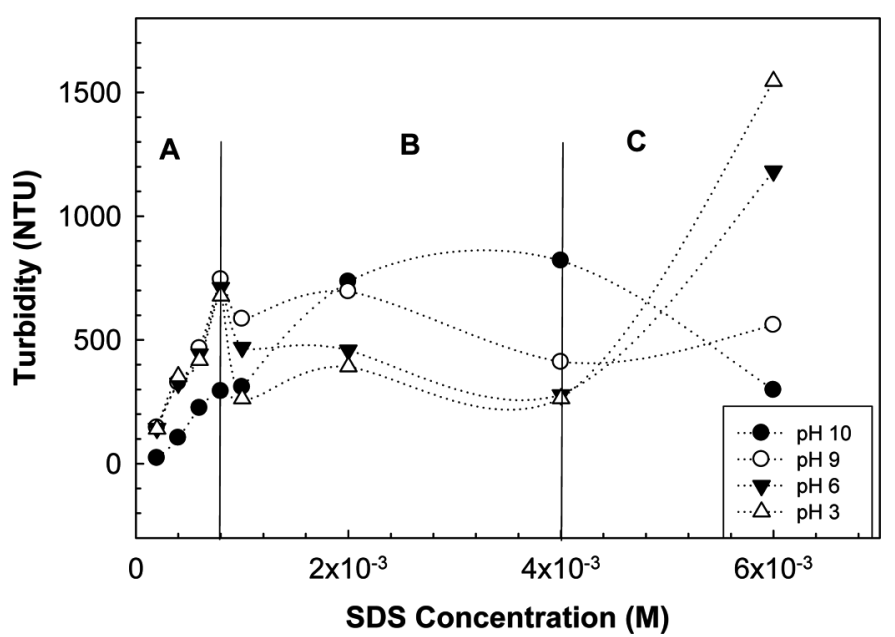

FIG. 7. Influence of $\mathrm{pH}$ on the turbidity of SDS/PEI solution mixtures as a function of SDS concentration, PEI concentration $400 \mathrm{ppm}$. 
the natural $\mathrm{pH}$ value for most of the solution mixtures) compared to other $\mathrm{pH}$ values. In region $\mathrm{B}$, precipitation starts $\left(10^{-3} \mathrm{M}\right.$ SDS and $\left.\mathrm{pH} 9\right)$. It was observed that the structure of the precipitates depended on the surfactant concentration as well as the solution $\mathrm{pH}$. In this region slight decrease in turbidity values were obtained due to precipitate formation and sedimentation. Precipitation was more pronounced at $\mathrm{pH} 6$ and $\mathrm{pH} 3$, therefore, a further decrease was observed in turbidity values at this $\mathrm{pH}$ range. However, precipitation was not observed in SDS/PEI solutions at higher SDS concentration (SDS, $6 \times 10^{-3} \mathrm{M}>\mathrm{CMC}$ ) at all $\mathrm{pH}$ values. The effect of $\mathrm{pH}$ on the turbidity of SDS solution at $8 \times 10^{-3} \mathrm{M}$ is shown in Figure 4 (inset plot). Again, any precipitate formation was not observed at this concentration and an increase was observed in turbidity values as the $\mathrm{pH}$ decreased. The behavior of SDS/PEI mixtures at very high surfactant concentrations can be interpreted by the resolubilization due to repulsive micellar interaction. ${ }^{[4]}$

Bastardo et al. ${ }^{[32]}$ reported that a decrease in $\mathrm{pH}$ results in a strong association between PEI and SDS. The initial binding of SDS at pH 4.9 does not result in any changes in the polyelectrolyte conformation. As the surfactant association proceeds three-dimensional aggregates, involving several polyelectrolyte chains and SDS, can be formed. ${ }^{[32]}$ In the current study SDS/PEI complexation at high $\mathrm{pH}$ is driven by the cooperative interaction of the surfactant via uncharged nitrogen atoms of the amine groups. ${ }^{[33,4]}$ Additionally, hydrophobic interactions is the mechanism that dominates SDS/PEI interaction at high $\mathrm{pH} .{ }^{[4,34]}$

\subsection{Interfacial Properties of SDS/PEI Solutions}

Figure 8 demonstrates the surface tension values of pure SDS solutions as a function of surfactant concentration.

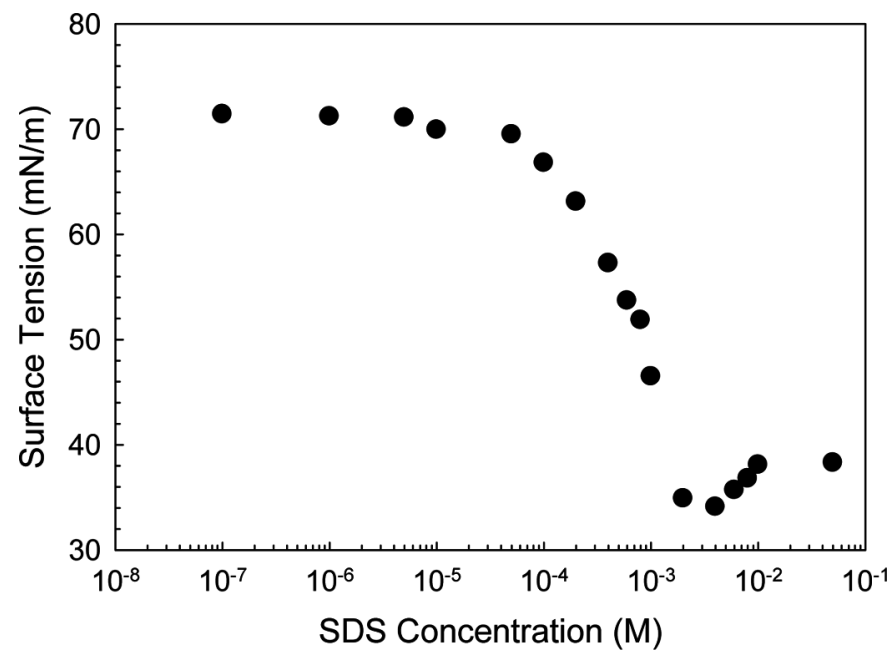

FIG. 8. Surface tension of pure SDS solutions as a function of concentration.
Results revealed that at high SDS concentrations the surface tension values were low and this is related with the higher surface activity. According to the Figure 8 critical micelle concentration (CMC) of SDS is about $4 \times 10^{-3} \mathrm{M}$ which is consistent with the literature values. The surface tension values of SDS solutions in the presence of PEI is given in Figure 9 as a function of surfactant and polyelectrolyte concentrations. Figure 9 shows that the surface tension values of SDS/PEI mixtures is much lower than the values of the pure SDS solutions. This is called synergistic effect and can be attributed to the strong Coulombic interactions between polyelectrolyte and oppositely charged surfactant head groups. This effect can be observed at low surfactant concentrations where pure surfactant alone does not adsorb at the surface ${ }^{[5,10]}$ Furthermore, strong surface complexation can be inferred from the suppression of the surface tensions at low surfactant concentrations. ${ }^{[35]}$ Results also showed that there is shift in CMC values of the mixtures depending on the PEI concentration. The change in CMC

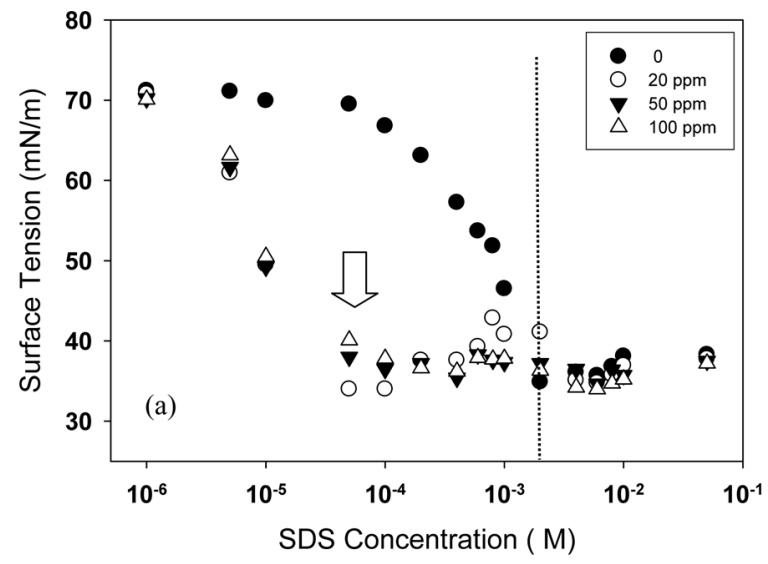

(a)

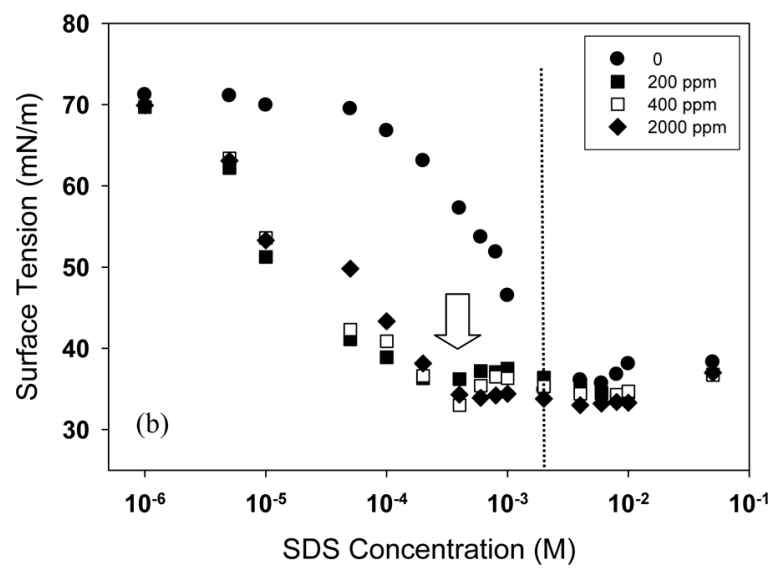

(b)

FIG. 9. Effect of PEI concentration on the surface tension of SDS/PEI solution mixtures (a) PEI concentration between $1 \mathrm{ppm}$ and $100 \mathrm{ppm}$ and (b) PEI concentration between 200 and $2000 \mathrm{ppm}$. 
was not so high for the polymer/surfactant mixtures containing high amount of PEI. At a PEI concentration of $20 \mathrm{ppm}$ there is evidence of a peak in the surface tension curve at about $10^{-3} \mathrm{M}$. According to the Figure 9, the $\mathrm{CMC}$ of the mixture is lower than $10^{-4} \mathrm{M}$ for PEI concentrations up to $100 \mathrm{ppm}$. Above this PEI concentration a shift in CMC was observed to higher concentrations $\left(>10^{-4} \mathrm{M}\right)$. Zakharova et al. reported that the polymer-surfactant complexes in solutions exhibits surfactant properties so that even at low surfactant concentrations the surface tension at the liquid-air interface decreases sharply. ${ }^{[20]}$ Therefore, surface tension values of solutions containing SDS/PEI mixtures become lower compared to SDS solution without PEI. Above the CMC of the surfactant the surface tension of SDS/PEI mixtures increases but remains lower than that for a miceller surfactant solution. This may be attributed to the desorption of some SDS ions unbound to PEI from interface to the bulk solution. ${ }^{[20]}$

The strength of interactions between two surfactants in mixed systems can be determined by calculating the interaction parameter using the CMC's obtained from the surface tension to log concentration plots of aqueous solutions of individual surfactants and their mixtures. ${ }^{[36]}$ The molecular interaction parameter for the mixed surfactant-polyelectrolyte system can be calculated using the following equation based on the regular solution theory derived by Rubingh: $:^{10,36]}$

$$
\begin{gathered}
\frac{\left(\mathrm{X}_{1}^{\mathrm{M}}\right)^{2} \ln \left[\alpha \cdot C_{12}^{M} / \mathrm{X}_{1}^{\mathrm{M}} \mathrm{C}_{1}^{\mathrm{M}}\right]}{\left(1-\mathrm{X}_{1}^{\mathrm{M}}\right)^{2} \ln \left[(1-\alpha) \mathrm{C}_{12}^{\mathrm{M}} /\left(1-\mathrm{X}_{1}^{\mathrm{M}}\right) \mathrm{C}_{2}^{\mathrm{M}}\right]}=1 \\
\beta^{M}=\frac{\ln \left(\alpha \mathrm{C}_{12}^{\mathrm{M}} / \mathrm{X}_{1}^{\mathrm{M}} \mathrm{C}_{1}^{\mathrm{M}}\right)}{\left(1-\mathrm{X}_{1}^{\mathrm{M}}\right)^{2}}
\end{gathered}
$$

where $\mathrm{C}_{1}^{\mathrm{M}}, \mathrm{C}_{2}^{\mathrm{M}}, \mathrm{C}_{12}^{\mathrm{M}}$ are the $\mathrm{CMC}$ of surfactant 1 and polyelectrolyte 2 and their mixtures, respectively. $\mathrm{X}_{1}^{\mathrm{M}}$ mole fraction of the surfactant 1 in the total surfactant in the mixed micelle, $\alpha$ is the mole fraction of surfactant 1 in the total surfactant in the solution phase. $\beta^{\mathrm{M}}$ is a parameter measures the nature and extent of interaction between the surfactant and polymer molecules in the mixed micelle solution. Based on Equation (3), interaction parameter for the SDS/PEI system was calculated to be -3.21 . The synergism is present when the CMC in aqueous medium of any surfactant mixture is smaller than that of single surfactant. For the synergism in a surfactant mixture the interaction parameter must be negative. ${ }^{[10]}$

\subsubsection{Effect of $\mathrm{pH}$ on the Interfacial Properties}

Effect of $\mathrm{pH}$ on the surface tension of SDS/PEI solution mixtures is presented in Figure 10. A shift was observed in $\mathrm{CMC}$ of mixtures at low PEI concentrations (20 ppm). According to Figure 10a, as the $\mathrm{pH}$ decreases $\mathrm{CMC}$ values

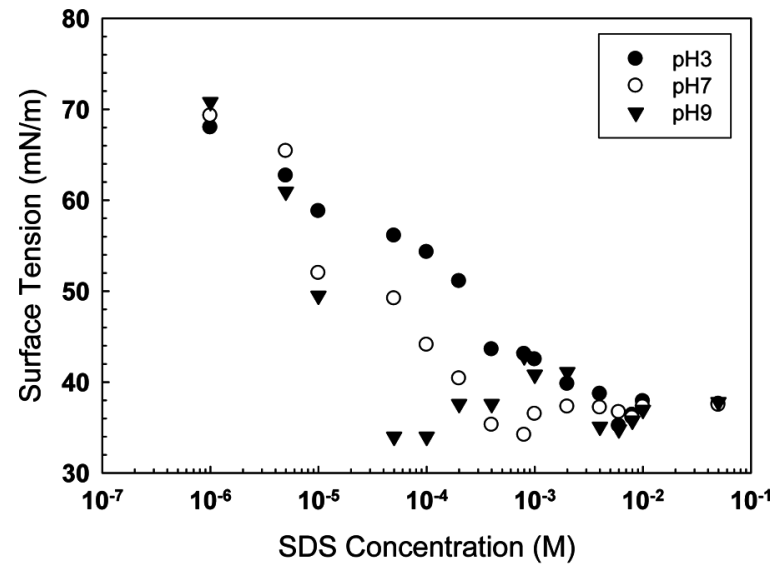

(a)

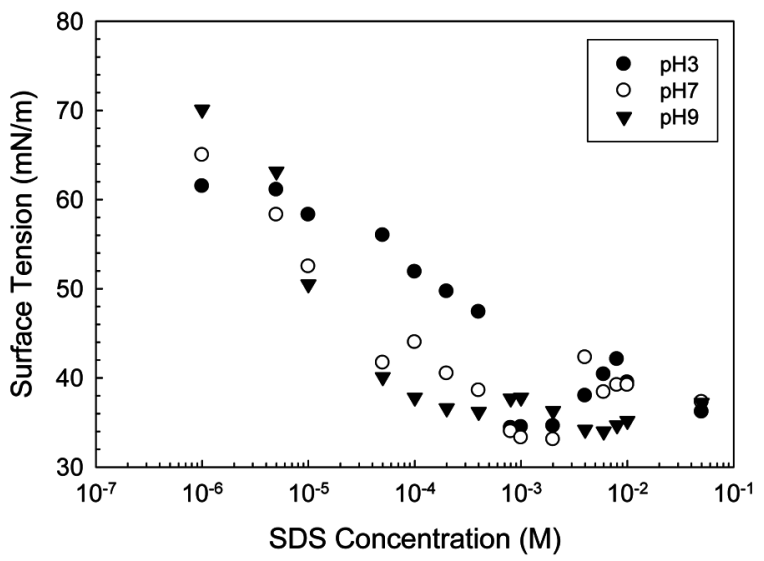

(b)

FIG. 10. Surface tension of SDS solutions in the presence of (a) $20 \mathrm{ppm}$ PEI and (b) $100 \mathrm{ppm}$ PEI at different $\mathrm{pH}$ values

shift to higher concentrations $\left(8 \times 10^{-3} \mathrm{M}\right.$ for $\mathrm{pH} 3$ and $8 \times 10^{-4} \mathrm{M}$ for $\mathrm{pH} 7$ ). On the other hand, the effect of $\mathrm{pH}$ on the surface tension of solutions containing high PEI concentration is not the same (see Figure 9b). Additionally, surface tension values are higher at $\mathrm{pH} 3 \mathrm{com}$ pared to the other $\mathrm{pH}$ values and this is valid for suspensions having both low and high PEI concentration. The difference between the surface tension values of SDS/PEI solutions is more pronounced at $\mathrm{pH} 9$ and in the presence of $20 \mathrm{ppm}$ PEI. The surface tension values obtained in this study is similar to that observed in nonionic polymer/ionic surfactant mixtures. ${ }^{[2]}$ Penfold et al. investigated the effect of $\mathrm{pH}$ on the surface tension of SDS/PEI mixtures. Results revealed that there is no shift in CMC depending on solution $\mathrm{pH}$ in the absence of electrolytes. ${ }^{[35]}$ However, in the current study $\mathrm{pH}$ showed pronounced effect on the surface properties of the SDS/PEI mixtures. In Figure 10, the distinct minimums observed in the surface tension values at all $\mathrm{pH}$ values may be attributed to the enhanced adsorption in these regions. On the other hand, the lack of serious change in the $\mathrm{CMC}$ values 
at $\mathrm{pH} 9$ and $\mathrm{pH} 7$ suggest that interaction between the SDS and PEI does not depend very much on $\mathrm{pH}$ at large PEI concentrations.

Winnik et al. ${ }^{[37]}$ reported that driving force for binding of SDS to PEI is electrostatic interaction at low pH. On the other hand adsorption at high $\mathrm{pH}$ is dominated by the hydrophobic interactions. Penfold et al. ${ }^{[21]}$ attributed the weak dependence of the adsorption on $\mathrm{pH}$ for SDS/PEI mixtures to the charge regulation effect and hydrophobic effect at high $\mathrm{pH}$.

\subsubsection{Effect of Electrolytes on the SDS/PEI Solution Mixtures}

The addition of an electrolyte to an ionic surfactant causes a decrease in electrostatic repulsion and facilitates micelle formation and micelle growth. The magnitude of these changes depends on the type and concentration of the electrolyte. ${ }^{[38]}$ Powale and Bhagwat reported that in aqueous solution of dodecyl sulfates the CMC decreases in the order of $\mathrm{Li}^{+}>\mathrm{Na}^{+}>\mathrm{Cs}^{+}{ }^{\left[{ }^{38]}\right.}$ It is also known that the adsorption of PEI on oppositely charged surfaces depends on the ionic strength of the system. ${ }^{[21]}$ Therefore, it is expected that both interfacial and bulk properties of SDS/PEI mixtures would be affected by the addition of electrolytes.

Figure 11 shows the surface tension values of the SDS/PEI mixtures in the presence of $0.1 \mathrm{M} \mathrm{NaCl}$ and $0.1 \mathrm{M} \mathrm{CaCl}_{2}$. By the addition of electrolytes a decrease was observed in surface tension values starting from low SDS concentrations compared to what is observed in the absence of electrolyte. This implies that the addition of electrolyte has increased the surface activity of the SDS/PEI complexes. Interfacial properties of solution mixtures in the presence of both electrolytes showed similar

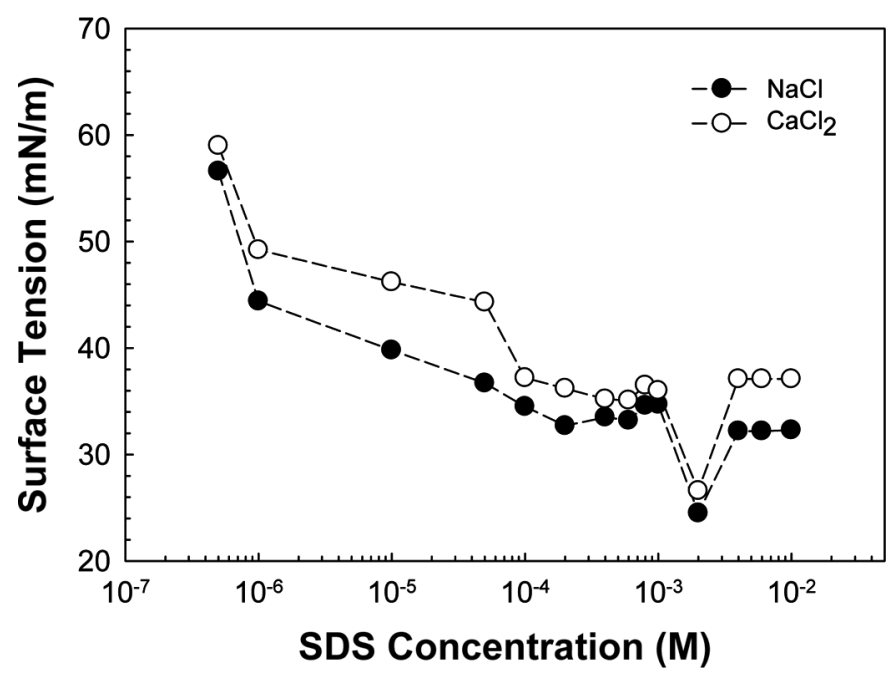

FIG. 11. Effect of $\mathrm{NaCl}(0.1 \mathrm{M})$ and $\mathrm{CaCl}_{2}(0.1 \mathrm{M})$ on the surface tension of SDS/PEI mixtures as a function of surfactant concentration; PEI (20 ppm), pH: 9.0-9.4. behavior. In the presence of $\mathrm{CaCl}_{2}$ surface tension values were lower compared to the values of $\mathrm{NaCl}$. For both cases $\mathrm{CMC}$ was at $2 \times 10^{-3} \mathrm{M}$ which is higher than the CMC of the mixture in the absence of electrolytes. CMC of mixture with the electrolytes is very close to the CMC of pure SDS solution shown in Figure 8. A steep decrease was observed in $\mathrm{pH}$ of the SDS/PEI solution mixture at $2 \times 10^{-3} \mathrm{M}$. In the presence of $\mathrm{NaCl}$ the $\mathrm{pH}$ of the solution dropped to 3.88 at this concentration. During the measurements precipitate formation was observed for SDS/PEI mixtures starting from $8 \times 10^{-4} \mathrm{M}$ SDS concentration in the presence of $\mathrm{CaCl}_{2}$.

Since the interaction between the polyelectrolyte and oppositely charged surfactant is mainly based on the electrostatic interactions the addition of salt have a significant influence on the complex formation between these species. According to the previous studies on this subject, addition of salt weakens the strength of complex formation which means that critical surfactant concentration for the onset of complex formation increases with increasing salt concentration. ${ }^{[18,21,29]}$ The addition of salt to a mixture of polymer surfactant mixture can directly induce the complex formation. Additionally, excess salt can completely restrict the complex formation. This effect can be explained based on the reduction or complete screening of the electrostatic attraction between SDS and PEI. ${ }^{[29]}$

\section{CONCLUSIONS}

Interactions between SDS and PEI were investigated in this study in bulk solution and at air-solution interface. Results showed that SDS/PEI/water system has unique properties which are not commonly observed in other anionic surfactant/cationic polyelectrolyte systems.

The turbidity measurements showed that SDS/PEI solution mixtures were transparent at low surfactant concentrations. With increasing SDS concentration, precipitate formation initiated then solutions became transparent again in excess SDS. Solution $\mathrm{pH}$ dramatically affected the complex formation and precipitation in bulk solution. The structure of the precipitates formed during micellazation was also $\mathrm{pH}$ depended. Three-dimensional complexes were obtained at high surfactant and PEI concentrations. Additionally, significant change in interfacial properties was observed depending on the solution $\mathrm{pH}$. A shift appeared in CMC values of SDS/PEI mixtures depending on the PEI concentration and the solution $\mathrm{pH}$. At low $\mathrm{pH}$ values (pH 3) an increase was seen in surface tension values of solution mixtures at all PEI concentrations.

Addition of $\mathrm{NaCl}$ and $\mathrm{CaCl}_{2}$ showed some influence on the interfacial properties of the solution mixtures. A decrease was observed in surface tension values which implies the increase in surface activity. Additionally, CMC of the solution mixture changed by the addition of electrolytes. 


\section{REFERENCES}

[1] Tsianou, M. and Alexandridis, P. (2005) In Surfactant-Polymer Interactions, Mixed Surfactant Systems, edited by M. Abe and J. Scamehorn; 2nd ed. Boca Raton, FL: CRC Press; Surfactant Science Series.

[2] Penfold, J., Thomas, R.K., and Taylor, D.J.F. (2006) $A d v$. Colloid Interface Sci., 11: 337-344.

[3] Schramm, L.L. (2000) Surfactants: Fundamentals and Applications in Petroleum Industry; Cambridge, UK: Cambridge University Press.

[4] Meszaros, R., Thompson, L., Bos, M., Varga, I., and Gilanyi, T. (2003) Langmuir, 19: 609-615.

[5] Jain, N., Trabelsi, S., Guillot, S., McLoughlin, D., Langevin, D., Letellier, P., and Turmine, M. (2004) Langmuir, 20: 8496-8503.

[6] Minatti, E., Norwood, D.P., and Reed, W.F. (1998) Macromolecules, 31: 2966-2971.

[7] Johal, M.S. and Chiarelli, P.A. (2007) Soft Matter, 3: 34-46.

[8] Bronich, T.K., Cherry, T., Vinogradov, S.V., Eisenberg, A., Kabanov, V.A., and Kabanov, A.V. (1998) Langmuir, 14: 6101-6106.

[9] Nagarajan, R. (2001) In Proceedings of New Horizons: Detergents for the New Millenium Conference; American Oil Chemists Society and Consumer Specialty Products Association, Fort Myers, FL, USA.

[10] Rosen, M.J. (1989) Surfactants and Interfacial Phenomena; New York: John Wiley and Sons.

[11] Bergstrom, M., Kjellin, U.R.M., Claesson, P.M., Pedersen, J.S., and Nielsen, M.M. (2002) J. Phys. Chem. B, 10: 11412-11419.

[12] Dedinaite, A., Meszaros, R., and Claesson, P.M. (2004) J. Phys. Chem. B, 108: 11645-11653.

[13] Bastardo, L.A., Garamus, M.V., Bergstrom, M., and Claesson, P.M. (2005) J. Phys. Chem. B, 109: 167-174.

[14] Phongikaroon, S., Hoffmaster, R., Judd, K.P., Smith, G.B., and Handler, R.A. (2005) J. Chem. Eng. Data, 50: 1602-1607.

[15] Sakagami, K., Yoshimura, T., and Esumi, K. (2002) Langmuir, 18: 6049-6053.

[16] Şakar-Deliormanl1, A. and Polat, H. (2004) In Proceedings of 10th International Mineral Processing Symposium; Mining Development Foundation of Turkey, Cesme, Izmir, Turkey, pp. 601-609.

[17] Giannis, A., Gidarakos, E., and Skouta, A. (2007) Desalination, 211: 249-260.

[18] Windsor, R., Neivandt, D., and Davies, P.B. (2001) Langmuir, 17: 7306-7312.
[19] Penfold, J.T., Tucker, I., Thomas, R.K., and Zhang, J. (2005) Langmuir, 21: 10061-10073.

[20] Zakharova, L.Y., Valeeva, F.G., Kudryavtsev, D.B., Bilalov, A.V., Tretýakov, A.Ya., Kudryavtseva, L.A., Konovalov, A.I., and Barabanov, V.P. (2005) Russ. Chem. Bull., 54: 641-649.

[21] Penfold, J., Tucker, I., Thomas, R.K., Taylor, D.J.F., Zhang, J., and Zhang, X.L. (2007) Langmuir, 23: 3690-3698.

[22] Bonini, M., Berti, D., Meglio, J.M.D., Almgren, M., Teixeirad, J., and Baglioni, P. (2005) Soft Matter, 1: 444-454.

[23] Andersson, K. and Bergstrom, L. (2000) J. Am. Ceram. Soc., 85: 2404-2408.

[24] Sadar, M.J. (1998) Turbidity Science, Technical Information Series Booklet; Loveland, CO: Hach Company, 11: 1-18.

[25] Griffiths, P.C., Paul, A., Fallis, I.A., Wellappili, C., Murphy, D.M., Jenkins, R., Waters, S.J., Nilmini, R., Heenan, R.K., and King, S.M. (2007) J. Colloid Interface Sci., 314: 460-469.

[26] Sakar-Deliormanli, A., Celik, E., and Polat, M. (2008) Colloids Surf. A, 324: 159-166.

[27] Bayrak, Y. (2003) Turk J. Chem., 27: 487-492.

[28] Claesson, P.M., Bergstrom, M., Dedinaite, A., Kjellin, M., Legrand, J.-F., and Grillo, I. (2000) J. Phys. Chem. B, 104: 11689-11694.

[29] Wang, X., Li, Y., Li, J., Wang, J., Wang, Y., Guo, Z., and Han, H. (2005) J. Phys. Chem. B, 109: 10807-10812.

[30] Mezei, A., Meszaros, R., Varga, I., and Gilanyi, T. (2007) Langmuir, 23: 4237-4247.

[31] Antonietti, M., Conrad, J., and Thunemann, A. (1994) Macromolecules, 27: 6007-6011.

[32] Bastardo, L.A., Meszaros, R., Varga, I., Gilanyi, T., and Cleasson, P.M. (2005) J. Phys. Chem. B, 109: 1619616202.

[33] Li, Y., Xu, R., Bloor, D.M., Holzwarth, J.F., and Wyn-Jones, E. (2000) Langmuir, 16: 10515-10520.

[34] Bystryak, S.M. and Winnik, M.A. (1999) Langmuir, 15: 3748-3751.

[35] Penfold, J., Tucker, I., Thomas, R.K., Taylor, D.J.F., Zhang, J., and Bell, C. (2006) Langmuir, 22: 8840-8849.

[36] Sharma, R., Varade, D., and Bahadur, P. (2003) J. Dispersion Sci. Technol., 24: 53-61.

[37] Winnik, M.A., Bystryak, S.M., and Chassenieux, C. (2000) Langmuir, 16: 4495-4510.

[38] Powale, S.R. and Bhagwat, S.S. (2006) J. Dispersion Sci. Technol., 27: 1181-1186. 